\title{
NUMERICAL INVESTIGATION OF NON-PREMIXED COMBUSTION INSIDE A THREE LAYERED POROUS BURNER WITH FLAMELET MODEL
}

\author{
Tanju ERGEN*, Tamer ŞENER**, Onur TUNCER*** and A. Cihat BAYTAŞ**** \\ Faculty of Aeronautics and Astronautics, Istanbul Technical University, 34467 Sariyer, Istanbul, \\ *ergent@itu.edu.tr, ORCID: 0000-0001-5049-0448 \\ **senerta@itu.edu.tr, ORCID: 0000-0002-1964-3263 \\ ***tuncero@itu.edu.tr, ORCID: 0000-0002-2803-1146 \\ ****baytas@itu.edu.tr, ORCID: 0000-0002-9660-5578
}

(Geliş Tarihi: 15.05.2020, Kabul Tarihi: 25.01.2021)

\begin{abstract}
Purpose of this study is to numerically investigate combustion within a porous channel, which has three layers with different pore densities. Non-premixed combustion inside the porous channel is modelled with thermal nonequilibrium energy equations. Flow and chemistry are decoupled with tabulated chemistry using flamelets, thereby reducing the computational cost. GRI 3.0 mechanism is used to account for methane/air combustion. Simulations are performed for different pore densities at the third layer in 8-30 PPI range. Also, the effects of thermal power and excessair-ratio (EAR) are investigated for the porous burner. Temperatures and species mass fraction distributions are obtained. Maximum temperature in the burner found to be similar for all cases since combustion occurs in stoichiometric conditions at the flame front as a result of the non-premixed combustion model. NOx and CO emissions values of all simulations are compared against international gas emission standards. This comparison showed that while $\mathrm{CO}$ emissions are always below all international standards, NOx emissions are below these limits only for high values of excess air ratio and thermal power. Besides, as the pore density of the third layer is decreased, the values of emissions decrease strongly.
\end{abstract}

Keywords: Porous media, Combustion, Flamelet model, Thermal Non-equilibrium

\section{ÜÇ KATMANLI GÖZENEKLİ YAKICIDA ÖN KARIŞIMSIZ YANMANIN FLAMELET MODELİ İLE SAYISAL İNCELENMESI}

Özet: Bu çalışmanın amacı üç farklı gözeneklilik yoğunluğuna sahip bir yakıcıyı sayısal olarak incelemektir. Bu kanalda ön karışımsız yanma, gözenekli katı ortam ile akışkan arasında 1sıl denge olmadığı kabülü ile 1sıl dengesiz enerji denklemleri kullanılarak modellenmiş̧tir. Yanma modelinde akış ve yanma mekanizmaları flamelet tablolama modeli ile ayrılmıştır ve böylece hesaplama maliyeti düşürülmüştür. Metanın hava ile yanması GRI 3.0 mekanizması ile modellenmiştir. Üçünçü gözenekli katmanın zararlı gaz salımına etkisini gözlemlemek için, son katmanın 8-30 PPI aralığında değiş̧en farklı gözeneklilik değerleri ile hesaplamalar yapılmıştır. Ek olarak, yakıcı gücünün ve fazla hava oranının yakıcıya etkisi de incelenmiştir. Hesaplamalar sonucunda sıcaklık dağılımı ve türlerin kütle kesirleri elde edilmiştir. Ön karışımsız yanmada tepkime tam oranlı şartlarda gerçekleşeceğinden yakıcı içerisindeki en yüksek sıcaklık her durum için benzer bulunmuştur. Yakıcının NOx ve CO salım değerleri uluslararası standartlar ile kıyaslanmıştır ve CO salımlarının her durumda standartların altında olduğu fakat NOx salımlarının sadece yüksek hava oranları ve 1sıl güçler ile düşük çıktığı görülmüştür. Ek olarak üçüncü katmanın gözenek yoğunluğu (PPI değeri) düşürüldükçe zararlı gaz salım değerlerinin de çokça düştüğü görülmüştür.

Anahtar Kelimeler: Gözenekli ortam, Yanma, Flamelet modeli, Isıl dengesiz model

\section{NOMENCLATURE}

$a_{g s} \quad$ Surface per unit volume $\left[\mathrm{m}^{-1}\right]$

$c_{p} \quad$ Heat capacity at constant pressure $\left[\mathrm{Jkg}^{-1} \mathrm{~K}^{-1}\right]$

$d_{p} \quad$ Pore diameter $[\mathrm{m}]$

$D_{z} \quad$ Mixture fraction diffusivity [-]

$h \quad$ Interfacial heat transfer coefficient $\left[\mathrm{Wm}^{-2} \mathrm{~K}\right]$

$h_{g s} \quad$ Volumetric heat transfer coefficient $\left[\mathrm{Wm}^{-3} \mathrm{~K}\right]$

$H \quad$ Total enthalpy of the mixture $\left[\mathrm{Jkg}^{-1}\right]$

$h_{i} \quad$ Enthalpy of $\mathrm{i}^{\text {th }}$ species $\left[\mathrm{Jkg}^{-1}\right]$

$k_{r} \quad$ Radiative conductivity [-]

$K \quad$ Permeability of porous media $\left[\mathrm{m}^{2}\right]$
$M W_{i} \quad$ Molecular weight of $\mathrm{i}^{\text {th }}$ species $\left[\mathrm{kg} \mathrm{mol}^{-1}\right]$

$N u_{v} \quad$ Volumetric Nusselt number [-]

$n \quad$ Normal direction [-]

$\boldsymbol{q}_{\boldsymbol{r}} \quad$ Radiation flux in solid region $\left[\mathrm{Wm}^{-2}\right]$

Re Reynolds number [-]

$P P C \quad$ Particles per centimeter $\left[\mathrm{cm}^{-1}\right]$

Pr Prandtl number [-]

$k$ Heat conduction coefficient $\left[\mathrm{Wm}^{-1} \mathrm{~K}^{-1}\right]$

Le Lewis number [-]

$\vec{u} \quad$ Fluid velocity $\left[\mathrm{ms}^{-1}\right]$ 


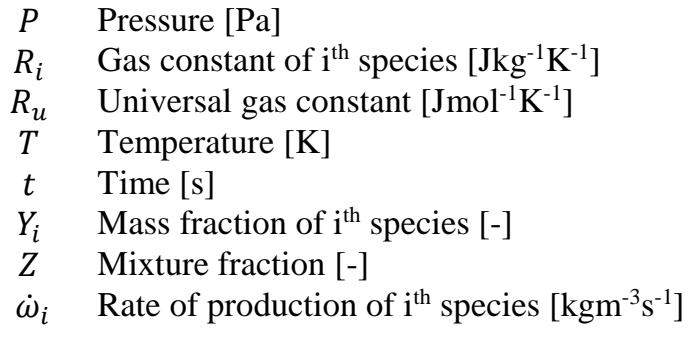

\section{Greek Symbols}

$\begin{array}{ll}\beta & \text { Emmisivity [-] } \\ \epsilon & \text { Porosity of porous media [-] } \\ \chi & \text { Scalar dissipation rate }\left[\mathrm{s}^{-1}\right] \\ \xi & \text { Enthalpy defect }\left[\mathrm{Jkg}^{-1}\right] \\ \sigma & \text { Stephan-Boltzmann constant [-] }\end{array}$

\section{INTRODUCTION}

Combustion within a porous burner is a relatively new technology. The most important feature of this technology lies within the inherent feedback mechanism of the heat released from combustion towards unburnt gases via a solid matrix, which in turn yields several advantages such as; the enhancement of flame stability, effective mixing of the reactants, high power density, complete combustion, enabling ultra-lean combustion regimes and thus reduction of thermal nitric oxide emissions. The equivalent pore diameter of porous media should be chosen carefully since the stability of combustion in porous media depends on the modified Peclet number. Stable combustion occurs only when the modified Pecklet number is over 65, otherwise flame cannot propagate in the porous media (Trimis et al., 2000).

To date, many numerical and experimental studies investigated pollutant emissions, operating limits and thermal efficiency of porous burners. Weinberg (1971) is one of the first researchers suggested that feedback of heat from burnt gases to unburnt gases can increase combustion efficiency and decrease the pollutant emission. Before the porous burner concept, the enhancement in heat feedback mechanism from burnt to unburnt gases was achieved by mixing a portion of burnt gases with unburnt gases. Takeno and Sato (1979b) introduced the idea of using porous media inside the combustion zone for the first time. Their mathematical model considers convection and conduction heat transfer while neglecting radiation and single-step global chemical reaction is used to account for combustion. In the same year, they conducted another study with experimental and numerical results where they included heat transfer with the environment in their mathematical model of the numerical solution (Takeno and Sato, 1979a). In porous burner technology, the idea of constructing the porous burner of two separate layers with different equivalent pore diameters was an important achievement (Hsu, Howell and Matthews, 1993).

\section{$\sigma_{s} \quad$ Extinction coefficient [-] \\ $\rho \quad$ Density $\left[\mathrm{kgm}^{-3}\right]$}

\section{Subscripts \\ $g \quad$ Gas phase \\ $s \quad$ Solid phase \\ $v \quad$ Volumetric \\ $p \quad$ Particle \\ $F \quad$ Fluid \\ $O$ Solid phase \\ $\infty \quad$ Ambient}

\section{Others \\ $<>$ Volume averaging}

There are one-dimensional studies investigating combustion inside porous media. Zhou and Pereira (1997) studied how burner power, excess air ratio, the conductivity of solid phase and radiation affects pollutant emissions and temperature profiles using a detailed methane-air reaction mechanism. Barra et al. (2003) investigated flame stabilization for two-layered porous burners. Their results showed that the operating limits are affected significantly by material properties such as thermal conductivity of solid phase, radiative extinction coefficient and heat transfer coefficient. Several onedimensional studies were also conducted by Bouma and De Goey (1999), Barra and Ellzey (2004), and Coutinho and de Lemos (2012).

Smucker and Ellzey (2005) investigated a porous burner with two layers numerically and experimentally. Experiments identified the stable operating envelope of the burner for propane and methane fuels. In the computational part of this study, only propane was investigated with a complete chemical mechanism for a one-dimensional porous burner. Another two-layered porous burner was investigated experimentally by Khanna, Goel and Ellzey (1994). Pollutant emissions were measured at the exit plane of the burner for different equivalence ratios, and results showed that both NOx and $\mathrm{CO}$ levels decreased with decreasing equivalence ratio.

Mishra et al. (2006) solved two different energy equations for gas and solid phases while investigating methane-air combustion numerically in two dimensions. Vijaykant and Agrawal (2007) studied liquid kerosene combustion for a two-layered porous burner with several configurations of SiC foam of different pore sizes. The aim of their study was reducing pollutant emissions. Baytas (2003) studied a non-Darcy porous medium with the thermal non-equilibrium assumption for natural convection in a square enclosure porous medium that generates heat. In another study, Baytas and Pop (2002) investigated thermal non-equilibrium model for free convection flow in a square cavity filled with a porous medium and compared their results for the local heat transfer rates with previous studies. 
In more recent studies, Keramiotis, Stelzner and Trimis (2012) performed a comprehensive experimental study to investigate thermal efficacy, pollutant emissions and stable operating range of a porous burner for methane and LPG. Shakiba et al. (2015) experimentally investigated the effects of foam properties on the porous burner performance. Experiments are conducted for different materials, pore densities and porosities. Their results showed that low emission values and high efficiencies were obtained when the burner is operated at low excessair-ratios for foams with high pore densities and high excess air ratios for foams with lower pore densities.

Understanding the combustion process is an important issue to obtain higher thermal power and lower pollutant emissions. Large number of chemical species and the widely disparate range of time-scales make the investigation of combustion with realistic chemical kinetics computationally expensive in numerical calculations ( $\mathrm{Lu}$ et al., 2009). In order to reduce this computational cost, methods that simplify the reaction kinetics based on partial-equilibrium and steady-state assumption, assuming that most chemical processes occur in much smaller time scales than the flow time scale have been developed.

Flamelet models are introduced for non-premixed combustion by Peters (1984). This approach decouples fluid dynamics and combustion chemistry via a tabulation approach. Flamelet tables are generated at a pre-processing step. Carbonell et al. (2009) studied both interactive and non-interactive flamelet models considering differential diffusion and non-differential diffusion conditions as well as adiabatic and nonadiabatic situations, and their square porous enclosure was studied using Darcy model and thermal nonequilibrium approach by Baytas (2003). Authors found that the thermal non-equilibrium model affects considerably the flow characteristics and heat transfer between solid and fluid phases in the porous matrix. The natural convection in a porous enclosure was examined using non-Darcian and the two-equation model (LNTE) by Khanna, Goel and Ellzey (1994). Authors studied the flow field by taking into account non-Darcian effects, Brinkman effect and Forchhiemer quadratic inertial effect. The effects of viscous dissipation on free convection in a porous cavity under thermal nonequilibrium case were examined by Baytas and Pop (2002). Their results showed that the average Nusselt number of the fluid decreases and the average Nusselt number of the solid increases by increasing the modified conductivity ratio. This result is valid for all of the viscous dissipation parameters. Barra and Ellzey (2004) investigated the effect of local thermal non-equilibrium (LTNE) state on the phenomenon of thermosolutal convection in a square porous enclosure with the nonDarcy model. They showed that the effect of LTNE model was meaningful for temperature distribution and the heat transfer rate; however, negligible on the mass transfer rate. Compared their results with detailed numerical calculations, Van Oijen and De Goey (2000) presented a method referred as Flamelet-Generated
Manifold (FGM) that can be considered as a combination of flamelet and manifold approaches to simplify chemical kinetics. Pope (2000) described a computational technique based on the In-Situ-AdaptiveTabulation (ISAT) of the accessed region of the combustion space that can decrease the computational cost of reacting flows with realistic chemical kinetics in numerical calculations.

The purpose of this study is to numerically investigate combustion inside a two-dimensional channel with three porous layers to obtain the effect of excess-air-ratios (EAR), thermal powers and different equivalent pore diameters for the third layer on CO and NOx emission. Combustion in porous media is modelled with the flamelet approach using the well-established GRI 3.0 mechanism (53 species, 325 reactions). Since temperature difference shall be recognizably high during combustion between solid and gas phases, non-thermal equilibrium model for energy equations in porous media are used. Thermophysical properties of both solid matrix and gas mixture are considered to be functions of temperature.

\section{MATHEMATICAL MODEL}

A two-dimensional rectangular porous burner is depicted in Figure 1.

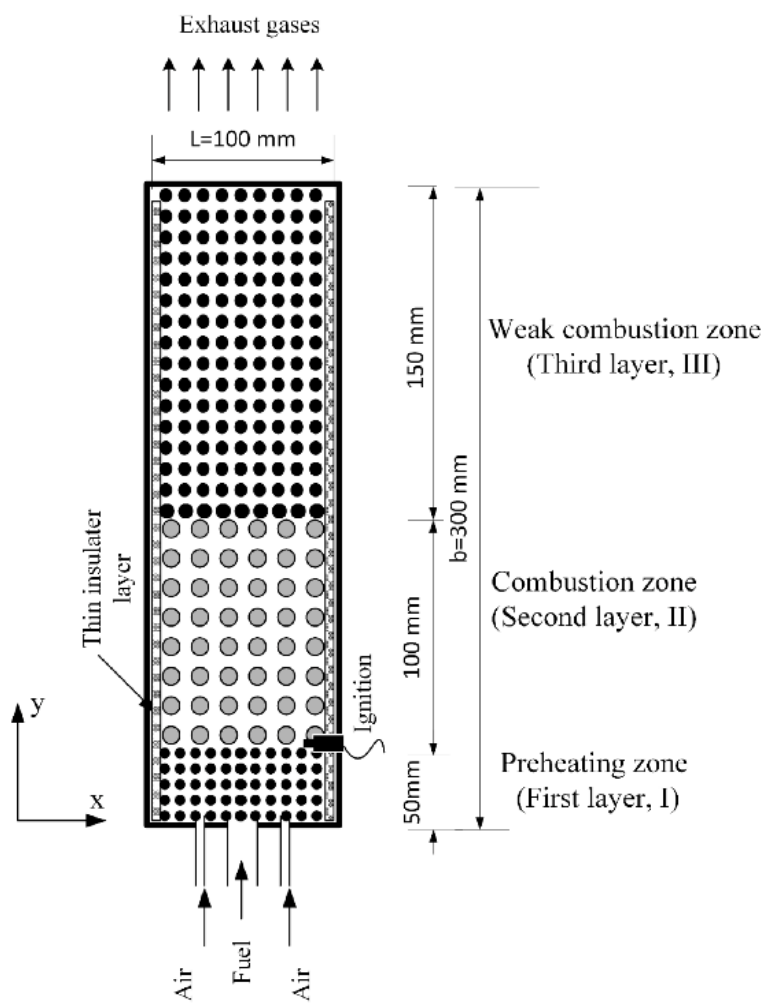

Figure 1. Schematic illustration of the porous burner.

The height and width of the porous channel are $b=300$ $\mathrm{mm}$ and $\mathrm{L}=100 \mathrm{~mm}$ respectively, and each inlet for air and fuel have the same width of $20 \mathrm{~mm}$. Vertical walls of the porous channel are insulated. There are three entrances at the bottom of the channel. The entrance in 
the middle belongs to fuel and the other two entrances belong to air. There is also ignition spark which is installed the interface of first and second porous layers. There are three layers in the channel of the porous burner with different porosities. The first layer is for preheating zone and its porosity is 20 PPI (Particle Per Inch). In this zone, combustion does not occur. The second layer is for the combustion zone and its porosity is 10 PPI. The third and last layer in the porous burner is for post-oxidation and its porosity range varies between 8-30 PPI. Porosity $(\varepsilon)$ of each layer is considered to be 0.85 . The fluid flow and combustion are considered to be unsteady and laminar. The Non-Darcian fluid flow model is used for a porous medium with local thermal non-equilibrium assumption.

The governing equations for fluid and porous layer can be presented as follows;

Continuity Equation;

$$
\epsilon \frac{\partial\langle\rho\rangle}{\partial t}+\nabla \cdot\langle\rho \vec{u}\rangle=0
$$

Where the angle brakets $(<>)$ denotes the volume averaging for solid and fluid phases.

Momentum Balance Equation;

$$
\begin{aligned}
& \frac{\rho_{g}}{\epsilon} \frac{\partial\langle\vec{u}\rangle}{\partial t}+\frac{\rho_{g}}{\epsilon^{2}}\langle\vec{u}\rangle \cdot \nabla\langle\vec{u}\rangle=-\nabla\langle p\rangle+ \\
& \frac{\mu_{g}}{\epsilon} \nabla^{2}\langle\vec{u}\rangle+\rho_{g} \boldsymbol{g}-\nabla\langle p\rangle^{g}
\end{aligned}
$$

where $\varepsilon$ is porosity of porous medium, $\mu_{\mathrm{g}}$ is the dynamic viscosity of the gas phase. The pressure loss due to porous matrix is taken into account using Ergun equation (1952) modified by Macdonald et al. (1979) as

$$
\nabla\langle p\rangle^{g}=180 \frac{(1-\epsilon)^{2}}{\epsilon^{3}} \frac{\mu\langle\vec{u}\rangle}{d_{p}^{2}}+1.8 \frac{1-\epsilon}{\epsilon^{3}} \frac{\rho|\langle\vec{u}\rangle|\langle\vec{u}\rangle}{d_{p}} .
$$

Mixture fraction equation is;

$$
\frac{\partial \epsilon \rho Z}{\partial t}+\nabla \cdot(\rho \vec{u} Z)=\nabla \cdot\left(\epsilon \rho D_{Z} \nabla Z\right) .
$$

Lewis number of mixture fraction, $\mathrm{Le}_{\mathrm{Z}} \approx 1$, is;

$$
L e_{Z}=\frac{k}{\rho D_{Z} c_{p}} \text {. }
$$

Scalar dissipation rate can be calculated with;

$$
\chi=2 D_{Z}(\nabla Z \cdot \nabla Z) .
$$

Thermal non-equilibrium energy equation for gas phase is;

$$
\begin{aligned}
& \rho_{g}\left\{\frac{\partial\left(\epsilon\langle H\rangle_{g}\right)}{\partial t}+\langle\vec{u}\rangle \cdot \nabla\langle H\rangle_{g}\right\}=\nabla . \\
& \left\{\frac{k_{g}}{c_{p_{g}}} \nabla\left(\epsilon\langle H\rangle_{g}\right)\right\}+h_{g s} a_{g s}\left(T_{s}-T_{g}\right) .
\end{aligned}
$$

Here $\mathrm{H}$ denotes enthalpy of the gas and $\mathrm{k}$ is the thermal conductivity. Enthalpy defect is calculated with the equation

$$
\xi=H-\left[H_{O}+Z\left(H_{F}-H_{O}\right)\right] \text {. }
$$

Here $\mathrm{H}_{\mathrm{o}}$ and $\mathrm{H}_{\mathrm{f}}$ represent air and fuel enthalpies, respectively. The thermal non-equilibrium energy equation for solid-phase is

$$
\begin{aligned}
& (1-\epsilon) \rho_{s} c_{p_{s}} \frac{\partial\langle T\rangle_{s}}{\partial t}=\nabla \cdot\left\{k_{s} \nabla(1-\epsilon)\langle T\rangle_{s}\right\}+ \\
& h_{g s} a_{g s}\left(T_{g}-T_{s}\right)-\nabla \cdot q_{r} .
\end{aligned}
$$

Here $h_{g s}$ and $a_{g s}$ are the convective heat transfer coefficient and the specific surface area or surface per unit volume between gas and solid phases which can be defined as

$$
a_{g s}=\frac{6(1-\epsilon)}{d_{p}} \text {. }
$$

Where $d_{p}$ is the mean pore diameter. It is approximated by the following equation suggested by $\mathrm{Fu}$ and Gore (1998)

$$
d_{p}=\frac{0.0254}{P P I} \sqrt{\frac{4 \epsilon}{\pi}} \quad(m) .
$$

$\nabla . \boldsymbol{q}_{\boldsymbol{r}}$ is the radiation flux in solid region and it can be defined as

$$
\boldsymbol{q}_{\boldsymbol{r}}=4 \frac{\sigma}{3 \sigma_{s}} \frac{\partial T_{s}^{4}}{\partial y}=\frac{16 \sigma T_{s}^{3}}{3 \sigma_{s}} \Delta T_{s}
$$

Where the bold terms show a vector quantities. The equation above is commonly known as Rosseland approximation or diffusion approximation since it is of the same type as Fourier's law of heat conduction (Modest, 1993). $\sigma$ is the Stephan-Boltzmann constant and it can be rearranged as

$$
\boldsymbol{q}_{\boldsymbol{r}}=-k_{r} \nabla T_{s}
$$

$\mathrm{k}_{\mathrm{r}}$ is described as radiation conductivity, and defined as

$$
k_{r}=-\frac{16 \sigma T_{s}^{3}}{3 \sigma_{s}}
$$

Radiation problem reduces to a simple conduction problem when conductivity is strongly temperaturedependent. In equation (14) $\sigma_{\mathrm{s}}$ is the radiation extinction 
coefficient for the $\mathrm{SiC}$ foam it can be calculated with $(\mathrm{Fu}$ and Viskanta R. Gore, 1998)

$$
\sigma_{s}=\frac{3}{d_{p}}(1-\epsilon)
$$

A correlation for $\mathrm{Nu}$ is proposed by Kuwahara, Shirota and Nakayama (2001) for laminar flow and ceramic foam as

$$
\begin{aligned}
N u_{g s}=\left(1+\frac{4(1-\epsilon)}{\epsilon}\right) & \\
& +\frac{1}{2}(1-\epsilon)^{\frac{1}{2}} \operatorname{Re}_{d_{p}} \operatorname{Pr}^{\frac{1}{3}}
\end{aligned}
$$

$0.2 \leq \epsilon \leq 0.9$.

$\mathrm{Nu}$, Re and $\mathrm{Pr}$ are Nusselt, Reynolds and Prandtl numbers, respectively. Reynolds number is based on the mean pore diameter, $d_{p}$. The solid properties, conductivity and specific heat are considered as functions of temperature, and they are calculated from the results of an experimental study (Rashed, 2002). Gas properties, viscosity and conductivity are also calculated as functions of temperature. Single component viscosity is given by the standard kinetic theory expression in a study (Hirschfelder, Curtiss and Bird, (1955))

$$
\mu_{k}=\frac{5}{16} \frac{\sqrt{\pi m_{k} k_{B}} T}{\pi \sigma_{k}^{2} \Omega^{2,2}}
$$

Here $\sigma_{\mathrm{k}}$ is the Lennard-Jones collision diameter, $\mathrm{m}_{\mathrm{k}}$ is the molecular mass, $\mathrm{k}_{\mathrm{B}}$ is the Boltzmann constant and $\Omega^{(2,2)}$ is the collision integral. After calculating viscosity for each species, gas mixture viscosity can be calculated using the equation

$$
\mu=\sum_{i=1}^{K} \frac{X_{i} \mu_{i}}{\sum_{j=1}^{K} X_{j} \phi_{i j}} .
$$

Where $\phi_{\mathrm{ij}}$ is defined as;

$$
\phi_{i j}=\frac{1}{\sqrt{8}}\left(1+\frac{W_{i}}{W_{j}}\right)^{-\frac{1}{2}}\left[1+\left(\frac{\mu_{i}}{\mu_{j}}\right)^{\frac{1}{2}}\left(\frac{W_{j}}{W_{i}}\right)^{\frac{1}{4}}\right]^{2}
$$

where $\mathrm{W}$ is molecular weight. Thermal conductivity of each species can be calculated using viscosity as,

$$
k_{i}=0.25\left(9 \gamma_{i}-5\right) \mu_{i} C_{v, i}
$$

Here $\gamma$ is the heat capacity ratio. Gas mixture conductivity can be calculated using each species conductivity.

The initial and boundary conditions of the simulation are listed below.

$\mathrm{t}=0$ (Initial conditions for the solution for entire domain)

$u_{x}=u_{y}=0, H=H_{\text {air }}, T_{s}=300 \mathrm{~K}, Z=0$

and $\mathrm{t}>0$ (Boundary conditions)

At the left and right walls;

$$
u_{x}=u_{y}=0, \frac{\partial H}{\partial x}=0, \frac{\partial T_{s}}{\partial x}=0, \frac{\partial Z}{\partial x}=0
$$

At the outlet;

$$
\begin{gathered}
u_{x}=0, \frac{\partial u_{y}}{\partial y}=0, \frac{\partial H}{\partial y}=0, \\
-k_{s} \frac{\partial T_{s}}{\partial y}=\sigma \beta\left(T_{s}^{4}-T_{\infty}^{4}\right), \frac{\partial Z}{\partial y}=0
\end{gathered}
$$

At the bottom wall:

$$
u_{x}=u_{y}=0, \frac{\partial H}{\partial y}=0, \frac{\partial T_{s}}{\partial y}=0, \frac{\partial Z}{\partial y}=0
$$

At the air inlet;

$$
\begin{gathered}
u_{x}=0, u_{y}=U_{O}, H=H_{O}, \\
-k_{s} \frac{\partial T_{s}}{\partial y}=\sigma \beta\left(T_{s}^{4}-T_{\infty}^{4}\right), Z=0
\end{gathered}
$$

At the fuel inlet;

$$
\begin{gathered}
u_{x}=0, u_{y}=U_{F}, H=H_{F}, \\
-k_{s} \frac{\partial T_{s}}{\partial y}=\sigma \beta\left(T_{s}^{4}-T_{\infty}^{4}\right), Z=1
\end{gathered}
$$

\section{Laminar Flamelet Combustion Model}

The laminar flamelet model is one of the methods of modelling combustion for non-premixed flames (Peters, 1984). In this model, the flame is considered as the sum of thin, laminar and locally one-dimensional flamelets. Mengi et al. (2015) studied this combustion model with Sandia-D flame which is similar with considered problem in terms of flow time scales. Because flow time scales are much slower than combustion time scales, flow and chemistry decoupling with flameler is justifiable. Flamelet solutions can be computed from the solution of counter-flow diffusion flames or solving the following set of flamelet equations.

Species mass fraction equation is

$$
\frac{\partial Y_{i}}{\partial t}=\frac{1}{L e_{Z}} \frac{\chi}{2} \frac{\partial^{2} Y_{i}}{\partial Z^{2}}+\frac{\dot{w}_{l}}{\rho} .
$$

Here mixture fraction is an independent coordinate, $\mathrm{Y}_{\mathrm{i}}$ and $\left(\dot{w}_{l}{ }^{\circ}\right)$ denotes the mass fraction and mass formation of the $\mathrm{i}^{\text {th }}$ species, respectively. $\chi$ is scalar dissipation rate and $\mathrm{Z}$ is the mixture fraction.

Energy Equation is

$$
\frac{\partial T}{\partial t}=\frac{\chi}{2} \frac{\partial^{2} T}{\partial Z^{2}}-\frac{1}{\rho c_{p}} \sum_{i=1}^{n} h_{i} \dot{w}_{l}+\frac{Q}{C_{p}} .
$$

Here $Q$ represents energy transfer while $h_{i}$ denotes the specific enthalpy of the $i^{\text {th }}$ species. Before calculations, laminar flamelet tables are constructed by solving flamelet equations for non-adiabatic conditions as preprocess using OpenFoam with libOpenSmoke. Flamelet tables are generated for ten different enthalpy defect values in the range of -85 to $100(\mathrm{~kJ} / \mathrm{kg})$ and each enthalpy defect, tables are constructed for eleven scalar dissipation rate from an equilibrium state to quenching for better interpolation. 
Boundary conditions for flamelet look-up tables are given as follows; temperature is $294 \mathrm{~K}$, the pressure is 1 atm. Also, the mole fraction of $\mathrm{CH}_{4}$ is 1 for fuel and air consists of $21 \% \mathrm{~N}_{2}$ and $79 \% \mathrm{O}_{2}$.

In the present study, the scalar dissipation rate will be near zero in a quasi-laminar situation. As a result, the flamelet equations reduce to the thermodynamic equilibrium limit for slow flows. Therefore, equilibrium tables can be used for calculations.

Figure 2 shows the flamelets generated between equilibrium and quenching for both adiabatic and nonadiabatic conditions. As seen from Figure 2 quenching strain rate is $29 \mathrm{~s}^{-1}$ for adiabatic conditions. In the superadiabatic condition where enthalpy defect is $50 \mathrm{~kJ} / \mathrm{kg}$, quenching strain rate increases to $34 \mathrm{~s}^{-1}$ and it decreases to $25 \mathrm{~s}^{-1}$ for a negative enthalpy defect of $-50 \mathrm{~kJ} / \mathrm{kg}$.

In the flamelet approach, the gas mixture temperature is determined by interpolation of mixture fraction, scalar dissipation rate and enthalpy defect values using previously generated flamelet tables. This approach does

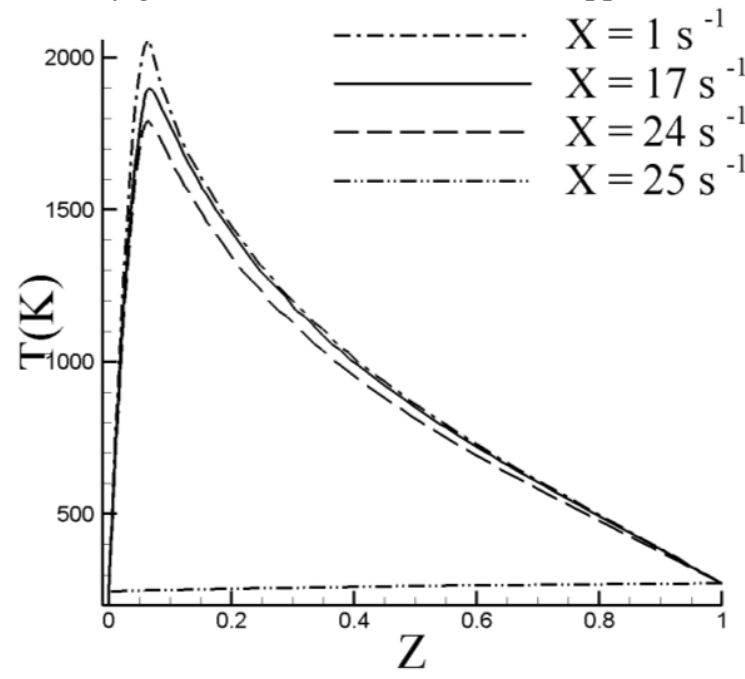

(a) not include combustion chemistry to flow field calculations; therefore, for complex combustion mechanisms, this is a great advantage in terms of computation time.

\section{Numerical Solution}

For the spatial discretization of the governing equations, a finite volume method is employed. The solution domain is discretized with collocated, uniform, and structured quadrilateral elements. Velocity and pressure are coupled with the SIMPLE algorithm (Patankar, 1980), and simulations are run via in-house code.

The resulting system of algebraic equations is arranged with the ADI method and solved with the usage of the tridiagonal matrix algorithm. To check the mesh independency of the results, centerline temperatures of solid and liquid phases that are obtained with three different mesh sizes compared.

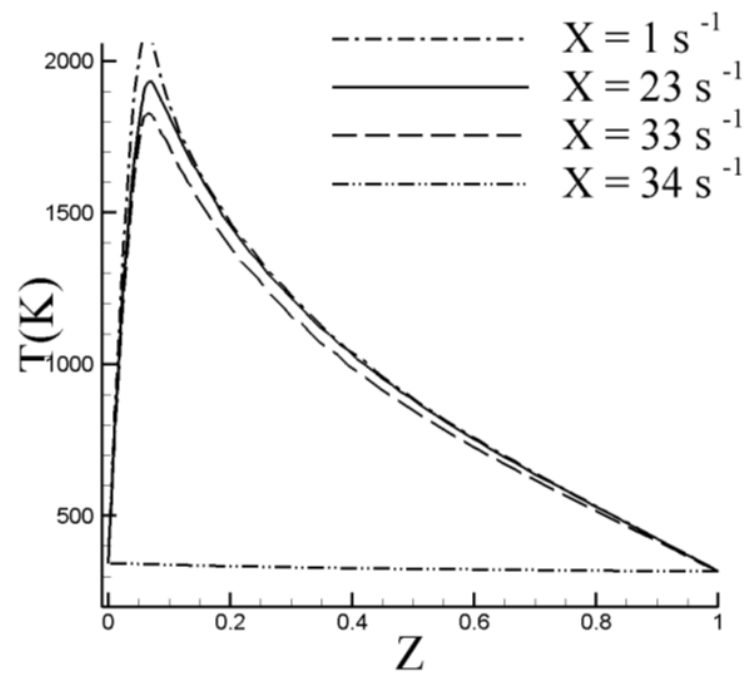

(b)

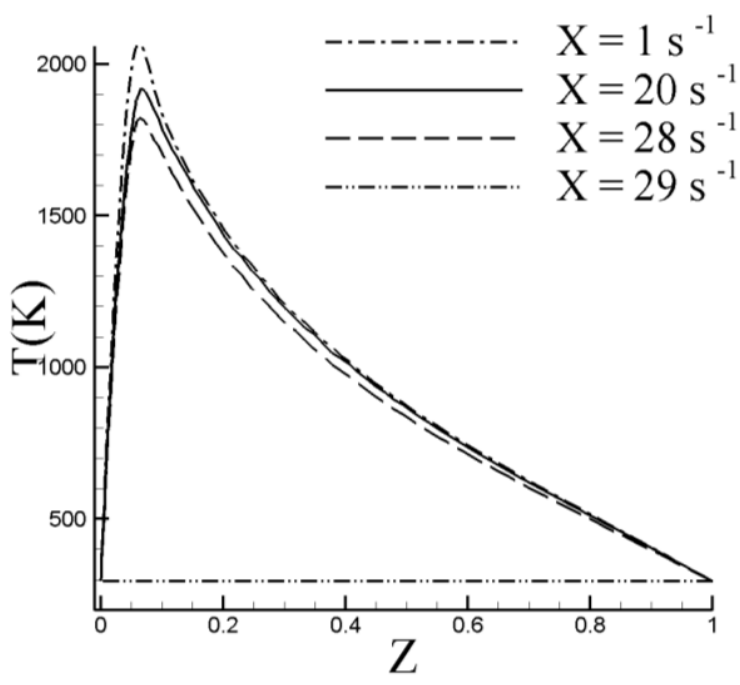

(c)

Figure 2. Flamelets for adiabatic and non-adiabatic conditions. (a) $\xi=-\mathbf{5 0} \boldsymbol{k J} / \boldsymbol{k g}$ (b) $\boldsymbol{\xi}=\mathbf{0} \boldsymbol{k J} / \boldsymbol{k g}$ (c) $\boldsymbol{\xi}=\mathbf{5 0} \boldsymbol{k J} / \boldsymbol{k g}$ 
Figure 3 represents the results of an accuracy test conducted using three sets of grids for gas phase since solid phase graph has the same trend. As seen from the comparison of centerline temperature profiles, there is an insignificant difference between the results for 104x204 and 156x306 grid densities.

Figure 4 shows numerical results in comparison with other numerical and experimental data obtained by Farzaneh et al. (2012) and Durst, Trimis and Pickenacker (1996), respectively. For this study, maximum temperature is observed at the flame front since combustion occurs at stoichiometric conditions as a result of non-premixed combustion Turns (1996). Farzaneh et al.'s study includes a heat-exchanger which affects the entire flow domain since the governing equations of the system are elliptic in nature. Therefore, even thought the heat-exchanger of their study is located at the end of their channel the effect of heat extraction can be observed within the all channel. As a result, the difference between present results and the others can be explained with the effects of heat-exchanger presence in the other studies.

Even though other studies have heat exchanger at the third layer which affects all domain; in the second layer, temperature profiles seem to have similar behavior after the peak temperature but then temperature decreases drastically in the third layer because of the presence of a heat exchanger in Farzaneh's study.

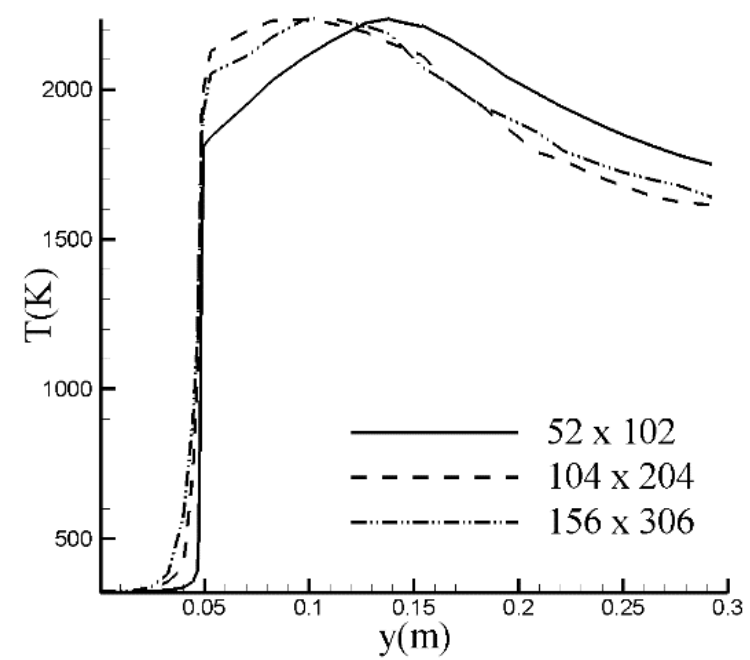

Figure 3. Centerline temperature profiles of gas phase for different grid sizes.

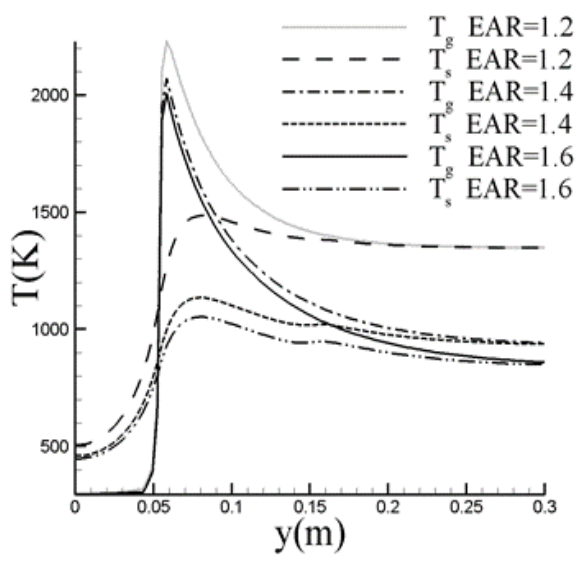

(a) $\varepsilon_{3}=8 \mathrm{PPI}$

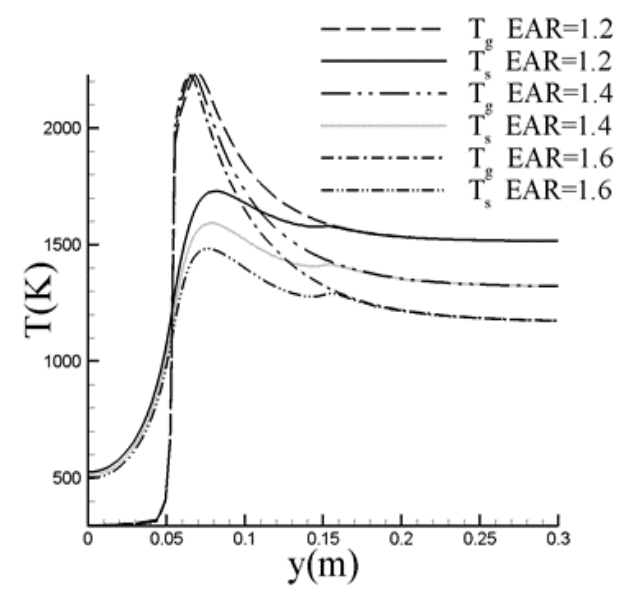

(c) $\varepsilon_{3}=30 \mathrm{PPI}$

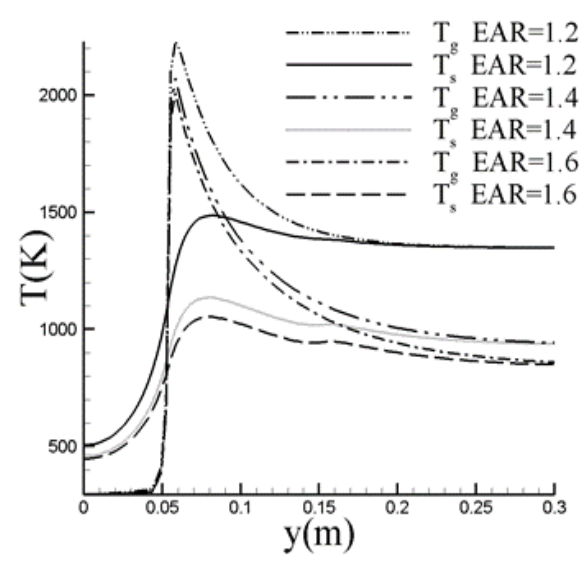

(b) $\varepsilon_{3}=10 \mathrm{PPI}$

Figure 5. Temperature profile comparison for excess-air-ratio inside the $15 \mathrm{~kW}$ porous burner with three different porosities for the third layer (a) $\varepsilon_{3}=8$ PPI (b) $\varepsilon_{3}=10$ PPI (c) $\varepsilon_{3}=30$ PPI. 


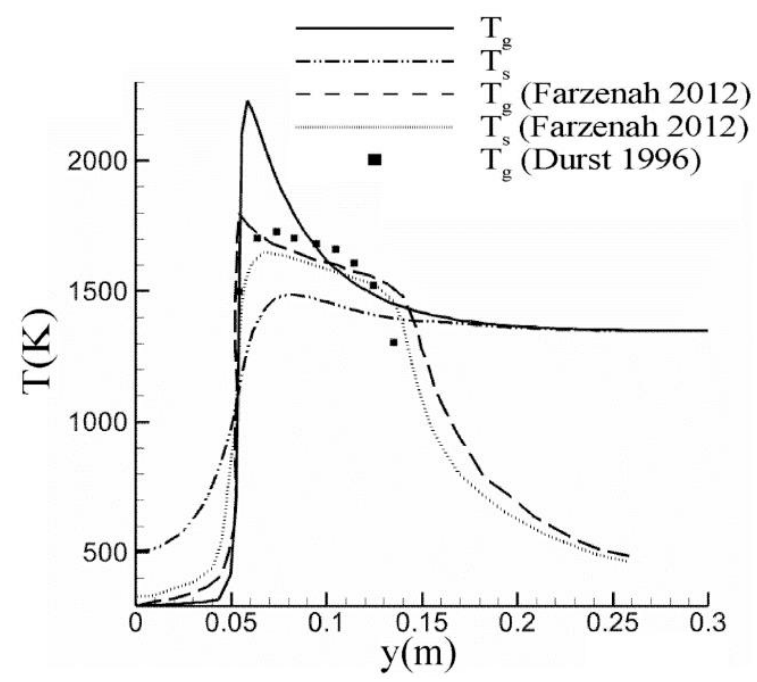

Figure 4. Comparison of calculated and experimental centerline temperature profiles for excess-air-ratio of 1.6.

\section{RESULTS AND DISCUSSION}

In this study, non-premixed combustion in a porous burner is investigated with the laminar flamelet approach with non-equilibrium energy model of gas and solid phases. The investigated porous burner has three layers with different pore densities. Effect of thermal power, excess air ratio, and pore density at the third layer on $\mathrm{CO}$ and NOx emission is studied. To examine the effect of the third layer pore density; 3 different pore density is chosen which are 8 PPI, 10 PPI and 30 PPI. On the other hand, to examine the thermal power effect on emission, it is chosen in a range between $12.5 \mathrm{~kW}$ to $20 \mathrm{~kW}$. Thermal power is adjusted by changing the mass flow rates of both fuel and air, and equivalence ratio (thus excess-air-ratio) is kept constant.

In Figure 5, temperature profiles are presented in the centerline of the channel for different excess-air-ratios. Increasing the excess-air-ratio resulted in exit gas temperature to decrease since the power of the burner kept constant while the total mass flow rate is increased. Another result of increasing excess-air-ratio is that the flame front moves backwards for higher excess-airratios.

Temperature distribution along the axial direction is presented for three different pore density values on the third layer of the burner in Figure 6. It shows that increasing the PPI of the third layer of the burner causes higher gas temperatures at the exit. Also, the flame front moves forward for higher PPI values of the third layer. Neither pore diameter nor excess-air-ratio affects the maximum temperature in the burner since combustion occurs at stoichiometric conditions at the flame front.

In Figure 7, temperature distribution in axial direction is compared for different thermal powers of the burner. As a result of increasing velocity, the flame front moves backwards, and the temperature of the gas mixture decreases at the exit of the burner. Again, the maximum temperature in the burner is not affected by velocity change. Figure 7 also shows clearly that the heat transfer coefficient between the gas and the solid phase is increasing with pore density. There is a sudden change in solid temperature profile at the beginning of the third layer at $\mathrm{y}=150 \mathrm{~mm}$.

Mass fraction of major species in vertical direction centerline is presented in Figure 8. As mentioned before this figure shows that combustion occurs at stoichiometric conditions as oxygen and methane fraction goes zero at the flame front.occcurs at stoichiometric conditions at the flame front as a result of non-premixed combustion.

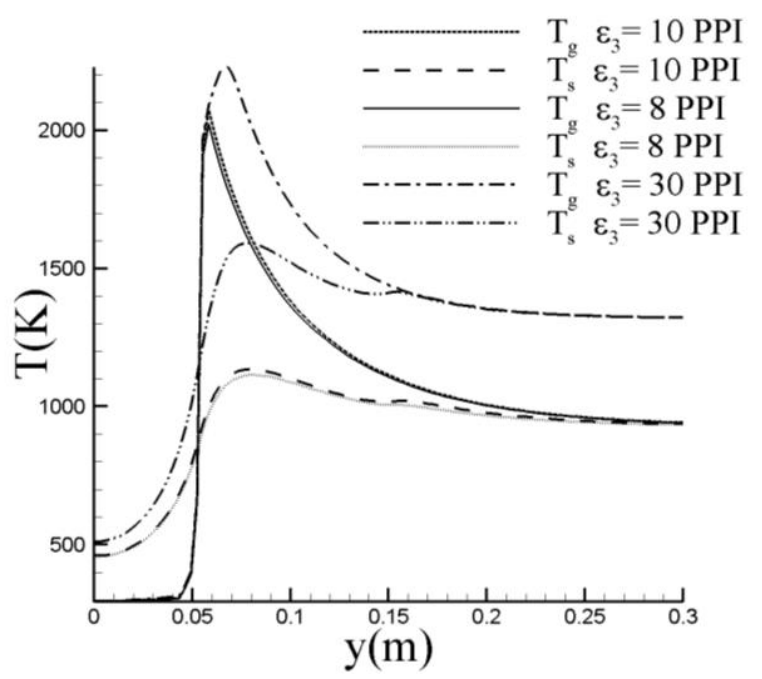

Figure 6. Temperature profiles comparison for the $15 \mathrm{~kW}$ porous burner with three different porosities for the third layer with excess air ratio 1.4 .

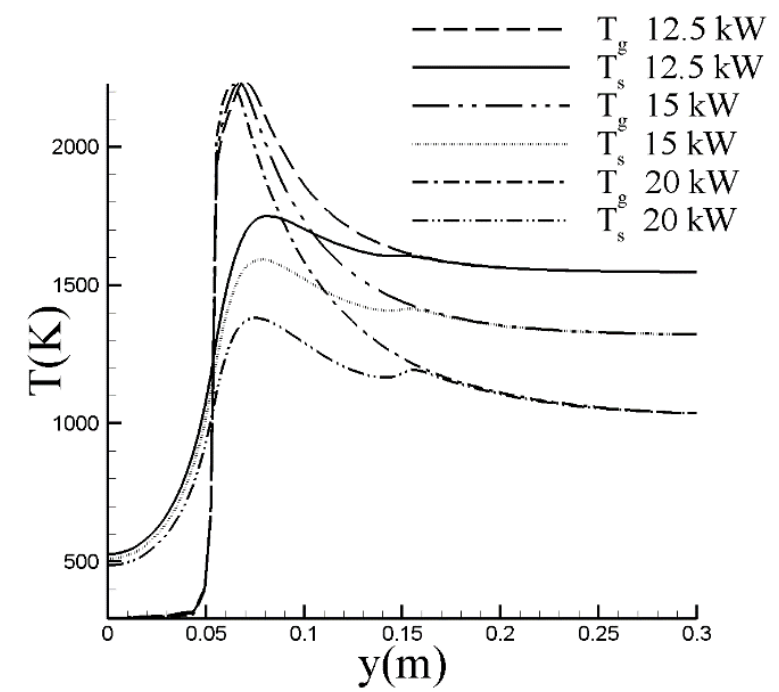

Figure 7. Temperature profiles comparison for different thermal power with excess air ratio 1.4 and third layer porosity 30 PPI. 


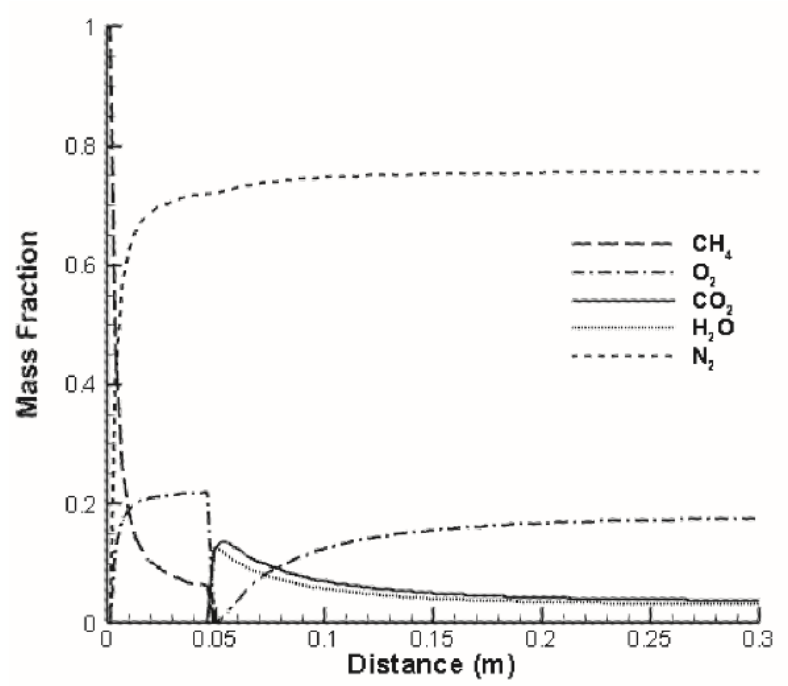

Figure 8. Mass fraction distribution of the major species at centerline of the burner.

Enthalpy defect distribution is shown in Figure 9. Since heat transfer between gas and solid phase is taken into account with the thermal non-equilibrium model, combustion does not occur adiabatically inside the porous burner. Positive values of enthalpy defect mean that combustion occurs in super-adiabatic conditions.

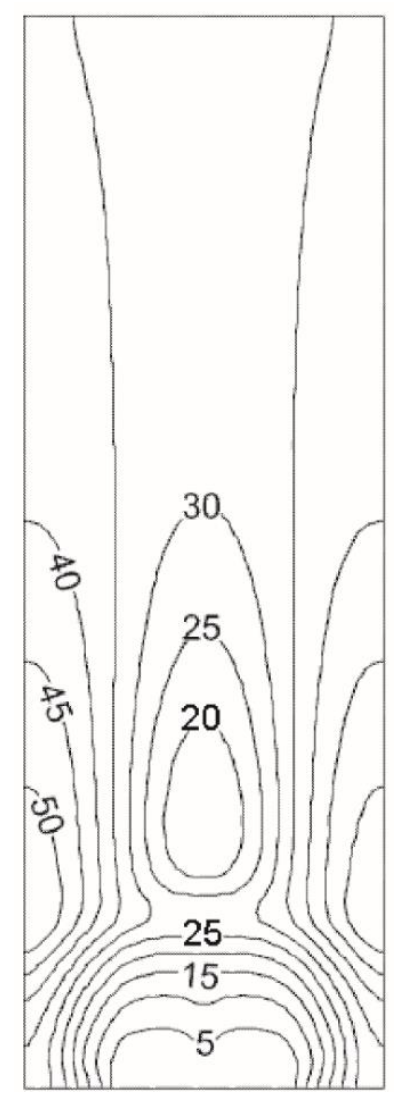

Figure 9. Enthalpy defect distribution inside the burner $(\mathrm{kJ} / \mathrm{kg})$.

Temperature isotherms inside the porous burner are shown for gas and solid phases in Figure 10. As expected, the combustion does not occur in the first layer because of the small equivalent pore diameter. The heat feedback mechanism works successfully as seen in Figure 10.
In Table 1, international gas emission standards are presented to compare with the results of this study. Comparison of these results with international gas standards shows that $\mathrm{CO}$ emissions of the porous burner are always within the limits of all standards for each pore density and excess air ratio. On the other hand, NOx emissions are not always in compliance with standards. When combustion occurs in low excess-air-ratios with high pore density at the third layer of the burner NOx emission exceeds the limits. However, if the EAR is increased or pore density of the third layer is decreased, the emission values of NOx and CO decreases dramatically below the limits of international gas emission standards.

In Table 2, gas emissions are compared for different pore densities at the third layer of the porous burner and results are given for various excess air ratios. It can be seen from the table that increasing pore density in the third layer of the burner leads to higher gas pollutant emissions. Even a small change in pore density such as from 8 PPI to 10 PPI cause higher emission values. This result is valid for both $\mathrm{NO}_{\mathrm{x}}$ and $\mathrm{CO}$ emissions for each excess air ratio.

In Table 3, gas emissions are compared for different thermal powers of the porous burner where combustion occurs at four different excess air ratios. The results of $\mathrm{CO}$ emission for each simulation seem to be below the limits of all compared international standards but NOx emissions exceed the standards for small values of EAR and thermal power. Operating the burner at higher thermal powers results in less pollutant emission.

\section{CONCLUSION}

In this study, the non-adiabatic flamelet approach is applied to model combustion in the porous burner. Simulations are conducted for thermal powers from 12.5 $\mathrm{kW}$ to $20 \mathrm{~kW}$ with EAR ranges from 1.2 to 1.8 . Based on the numerical results, the following conclusions can be drawn.

- Pore density at the third layer of the burner is an important parameter that can affect the temperature distribution and pollutant emissions dramatically. Increasing the pore density at the third layer helps to keep the heat inside the porous burner extracting more heat from the combustion products. This is an important observation in terms of design of practical porous media combustors.

- Effect of thermal power of the porous burner was also investigated in this study and results showed that operating the porous burner at higher thermal power leads to a decrease in pollutant emissions within the range of conducted simulations.

- Enthalpy defect distribution shows that combustion occur in super-adiabatic conditions which results to higher combustion temperature and therefore higher pollutant emissions. 
- Flamelet model is used for modeling combustion inside a porous medium. With this approach, methane-air reaction is solved using GRI 3.0 mechanism but complexity of the chemical reactions was not involved in the computations since it was tabulated in the preprocessing process. Tabulated chemistry approach speeds up computations.

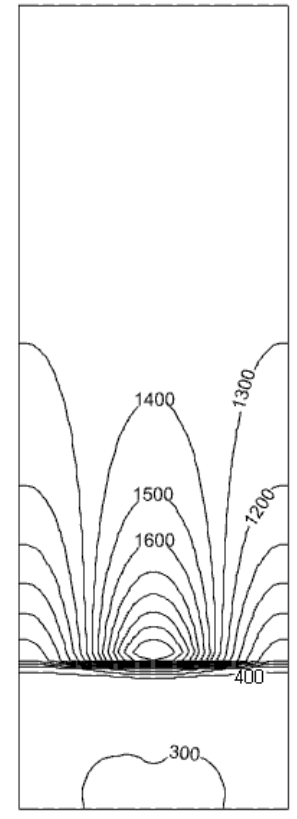

$T_{g}$

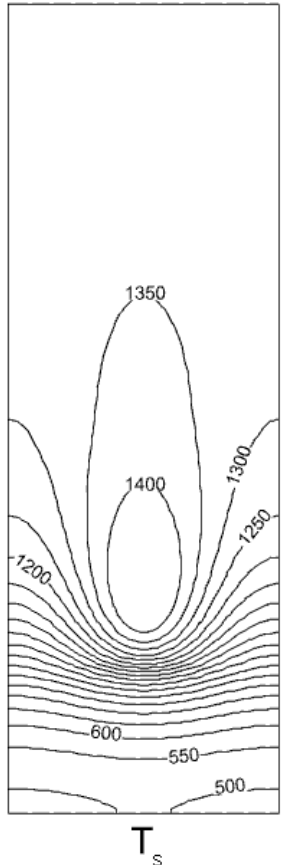

(a)

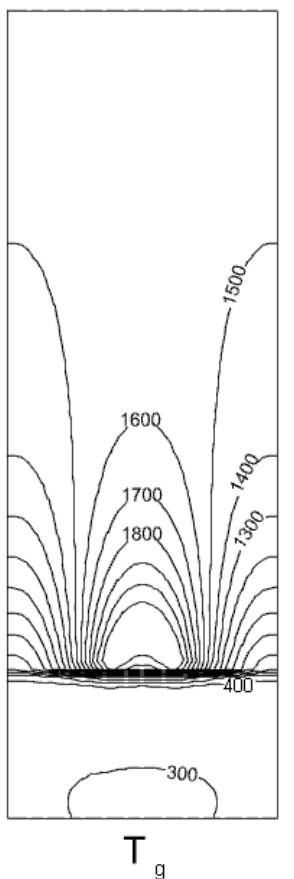

-Increasing the excess-air-ratio always decreased the exit temperature of the gas mixture and the pollutant levels.

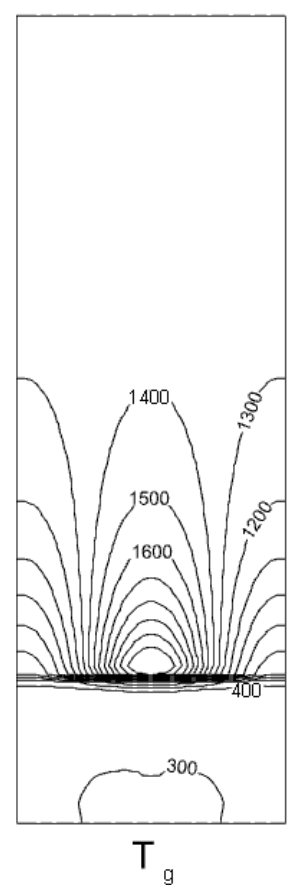

(b)

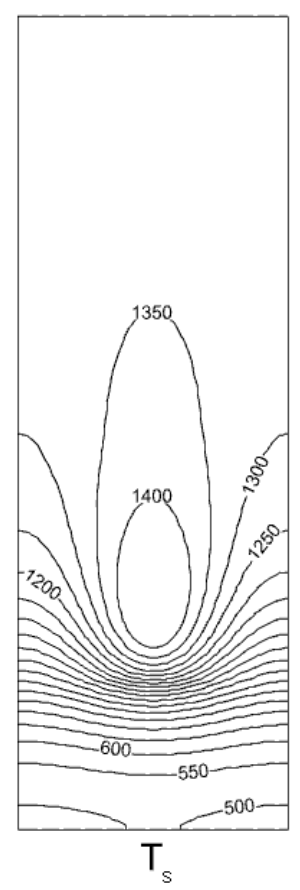

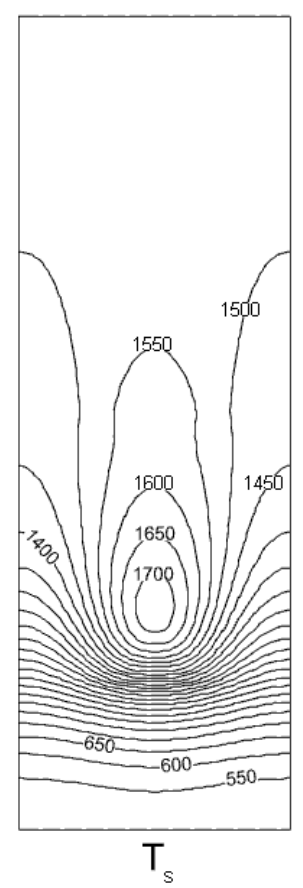

(c)

Figure 10. Isotherms of gas and solid phases temperatures for the $15 \mathrm{~kW}$ porous burner with three different porosities at the third layer (a) $\varepsilon_{3}=8$ PPI (b) $\varepsilon_{3}=10$ PPI (c) $\varepsilon_{3}=30$ PPI. 
Table 1. International gas emission standards (Scheffler, Colombo and Wiley, 2005).

\begin{tabular}{|l|l|l|l|l|}
\hline & DIN 4702 & Swiss Standard & Blauer Engel & $\begin{array}{l}\text { Hamburg } \\
\text { Promoting }\end{array}$ \\
\hline $\mathrm{NOx}(\mathrm{mg} / \mathrm{kWh})$ & 200 & 80 & 60 & 20 \\
\hline $\mathrm{CO}(\mathrm{mg} / \mathrm{kWh})$ & 100 & 60 & 50 & 10 \\
\hline
\end{tabular}

Table 2. Gas emission comparison for $15 \mathrm{~kW}$ porous burners with different PPI at the third layer.

\begin{tabular}{|c|c|c|c|}
\hline & EAR 1.2 & EAR 1.4 & EAR 1.6 \\
\cline { 2 - 4 } & \multicolumn{3}{|c|}{ NOx Emission (mg/kWh) } \\
\hline 8 PPI & 201.24 & 16.43 & 6.12 \\
\hline 10 PPI & 210.32 & 16.49 & 6.22 \\
\hline 30 PPI & 409.02 & 216.35 & 103.67 \\
\hline & \multicolumn{3}{|c|}{ CO (mg/kWh) } \\
\hline 8 PPI & 0.03 & 0 & 0 \\
\hline 10 PPI & 0.03 & 0 & 0 \\
\hline 30 PPI & 0.04 & 0.03 & 0 \\
\hline
\end{tabular}

Table 3. Gas emission comparison of the porous burner with 30 PPI third layer for different thermal powers

\begin{tabular}{|c|c|c|c|c|}
\hline & EAR 1.2 & EAR 1.4 & EAR 1.6 & EAR 1.8 \\
\cline { 2 - 5 } & \multicolumn{4}{|c|}{ NO Emission (mg/kWh) } \\
\hline $12.5 \mathrm{~kW}$ & 658.69 & 443.92 & 262.47 & 144.62 \\
\hline $15 \mathrm{~kW}$ & 409.02 & 216.35 & 103.67 & 50.64 \\
\hline $20 \mathrm{~kW}$ & 108.45 & 40.38 & 16.22 & 6.59 \\
\hline & 9.62 & 8.81 & CO (mg/kWh) & 4.16 \\
\hline $12.5 \mathrm{~kW}$ & 0.47 & 0.03 & 5.65 & 0 \\
\hline $15 \mathrm{~kW}$ & 0 & 0 & 0 & 0 \\
\hline $20 \mathrm{~kW}$ & \multicolumn{5}{|c|}{} \\
\hline
\end{tabular}

\section{ACKNOWLEDGEMENTS}

Authors gratefully acknowledge the support received from Turkish Scientific and Technical Research Council under contract no 114M672.

\section{REFERENCES}

Barra, A. J. and Ellzey, J. L. (2004) 'Heat recirculation, heat transfer in porous burners', Combust. Flame, 137, pp. 230-241.

Barra, A. J. et al. (2003) 'Numerical study of the effects of material properties on flame stabilization in a porous burner', Combust. Flame, 134, pp. 369-379. doi: 10.1016/S0010-2180(03)00125-1.

Baytas, A. C. (2003) 'Thermal Non-Equilibrium natural convection in a square enclosure filled with a heat generating solid phase, non-Darcy porous medium', International Journal of Energy Research, 27, pp. 975988. doi: 10.1002/er.929.

Baytas, A. C. and Pop, I. (2002) 'Free convection in a square porous cavity using a thermal nonequilibrium model', International Journal of Thermal Sciences, 41(9), pp. 861-870. doi: 10.1016/S1290-0729(02)01379-0.

Bouma, P. H. and De Goey, L. P. H. (1999) 'Premixed Combustion on Ceramic Foam Burners', Combust. Flame, 119, pp. 133-143. doi: 10.1016/S00102180(99)00050-4.
Carbonell, D. et al. (2009) 'Flamelet mathematical models for non-premixed laminar combustion', Combustion and Flame, 156(2), pp. 334-347. doi: 10.1016/j.combustflame.2008.07.011.

Coutinho, J. E. A. and de Lemos, M. J. S. (2012) 'Laminar flow with combustion in inert porous media', Int. Communications in Heat and Mass Transfer, 39, pp. 896-903.

doi: 10.1016/j.icheatmasstransfer.2012.06.002

Durst, F., Trimis, D. and Pickenacker, K. (1996) 'Compact porous medium burner and heat exchanger for household applications.', European Union commission project report, pp. 1-85.

Ergun, S. (1952) 'Fluid flow through packed columns', Chemical Engineering and Progress, 8(2), pp. 89-94.

Farzaneh, M. et al. (2012) 'Numerical investigation of premixed combustion in a porous burner with integrated heat exchanger', Heat and Mass Transfer. SpringerVerlag, 48(7), pp. 1273-1283. doi: 10.1007/s00231-0120966-1.

Fu, X. and Viskanta R. Gore, J. P. (1998) 'Measurement and corrolation of volumetric heat transfer coefficients of cellular ceramics.', Experimental Thermal and Fluid Science, 17, pp. 285-293. 
Hirschfelder, J. O., Curtiss, C. F. and Bird, R. B. (1955) 'Molecular theory of gases and liquids. Wiley, New York, 1954', Journal of Polymer Science, 17(83), p. 116. doi: 10.1002/pol.1955.120178311.

Hsu, P. F., Howell, J. R. and Matthews, R. D. (1993) 'A numerical investigation of premixed combustion within porous inert media', Journal of Heat Transfer, 115(3), pp. 744-750. doi: 10.1115/1.2910746.

Keramiotis, C., Stelzner, B. and Trimis D. Founti, M. (2012) 'Porous burners for low emission combustion: An experimental investigation', Energy, 45, pp. 213-219. doi: 10.1016/j.energy.2011.12.006.

Khanna, V., Goel, R. and Ellzey, J. L. (1994) 'Measurements of Emissions and Radiation for Methane Combustion with in a Porous Medium Burner', Combustion Science and Technology, 99, pp. 133-142. doi: 10.1080/00102209408935429.

Kuwahara, F., Shirota, M. and Nakayama, A. (2001) 'A numerical study of interfacial convective heat transfer coefficient in two-energy equation model for convection in porous media', International Journal of Heat and Mass Transfer. Pergamon, 44(6), pp. 1153-1159. doi: 10.1016/S0017-9310(00)00166-6.

Lu, L. et al. (2009) 'Computationally efficient implementation of combustion chemistry in parallel PDF calculations', Journal of Computational Physics. Academic Press, 228(15), pp. 5490-5525. doi: 10.1016/j.jcp.2009.04.037.

Macdonald, I. F. et al. (1979) 'Flow Through Porous Media: Ergün equation revisited', Indust. Eng. Chem. Fundamentals, 18, pp. 199-208. doi: 10.1021/i160071a001.

Mengi, S.,Tunçer, O., Baytaş, A.C., "Sandia-D Alevi Simülasyonunda Radyasyon Etkisinin Flamelet Modeli Kullanılarak İncelenmesi”, 20. Ulusal Is1 Bilimi ve Tekniği Kongresi, Balıkesir, Türkiye, Eylül 2015

Mishra, S. C. et al. (2006) 'Heat transfer analysis of a two-dimensional rectangular porous radiant burner', Int. Commun. Heat Mass Transfer, 33, pp. 467-474. doi: 10.1016/j.icheatmasstransfer.2005.12.006.

Modest, M. F. (1993) Radiative Heat Transfer. Mc Graw Hill International Editions. doi: 10.1017/CBO9781107415324.004.

Patankar, S. (1980) Numerical heat transfer and fluid flow. CRC press.

Peters, N. (1984) 'Laminar diffusion flamelet models in non-premixed turbulent combustion', Progress in Energy and Combustion Science. Pergamon, 10(3), pp. 319-339. doi: 10.1016/0360-1285(84)90114-X.
Pope, S. B. (2000) 'Computationally efficient implementation of combustion chemistry using in situ adaptive tabulation', Combustion Science and Technology, 161, pp. 113-137.

Rashed, A. H. (2002) 'Properties and characteristics of silicon Carbide’. Decatur, TX. doi: 10.5772/615.

Scheffler, M., Colombo, P. and Wiley (2005) Cellular ceramics: structure, manufacturing, properties and applications. Wiley-VCH. Available at: https://books.google.com.tr/books?hl=tr\&lr=\&id=LP6H pxX0A8MC\&oi=fnd\&pg=PR5\&dq=scheffer+colombo + cellular+ceramics+structure + manufacturing\&ots $=\mathrm{Z7Y}$ tG8TTBe\&sig=756Q5nXisaKWyg-

jWxIzhAOFZyI\&redir_esc=y\#v=onepage \&q=scheffer colombo cellular ceramics structure manufacturing \&f=false (Accessed: 27 September 2017).

Shakiba, S. A. et al. (2015) 'Effects of foam structure and material on the performance of premixed porous ceramic burner', Proceedings of the Institution of Mechanical Engineers, Part A: Journal of Power and Energy, 229(2), pp. 176-191. doi: 10.1177/0957650914558166.

Smucker, M. T. and Ellzey, J. L. (2005) 'Computational experimental study of two-section porous burner', Combust. Sci. Technol., 176, pp. 1171-1189. doi: 10.1080/00102200490457385.

Takeno, T. and Sato, K. (1979a) 'A theoretical and experimental study on an excess enthalpy flame', in ICOGER. doi: 10.1016/S0082-0784(81)80052-5.

Takeno, T. and Sato, K. (1979b) 'An Excess Enthalpy Flame Theory', - Combustion Science and Technology, 20(1-2), pp. 73-84. doi: 10.1080/00102207908946898.

Trimis, D. et al. (2000) Porous Medium Combustor versus Combustion Systems with Free Flames.

Turns, Stephen R. 'Introduction to combustion'. Vol. 287. McGraw-Hill Companies, 1996.

Van Oijen, J. A. and De Goey, L. P. H. (2000) 'Modelling of Premixed Laminar Flames using Flamelet-Generated Manifolds', Combustion Science and Technology, 161, pp. 113-137. doi: 10.1080/00102200008935814.

Vijaykant, S. and Agrawal, A. K. (2007) 'Liquid fuel combustion within silicon-carbide coated carbon foam', Exp. Therm. Fluid Sci., 32, pp. 117-125. doi: 10.1016/j.expthermflusci.2007.02.006.

Weinberg, F. J. (1971) 'Combustion Temperatures: The Future?', Nature, 233(5317), pp. 239-241. doi: $10.1038 / 233239 \mathrm{a} 0$

Zhou, X. Y. and Pereira, J. C. F. (1997) 'Numerical study on combustion and pollutions formation in inert non homogenous porous media', Combustion Sci. Technol., 130, pp. 335-364. doi: 10.1080/00102209708935748 

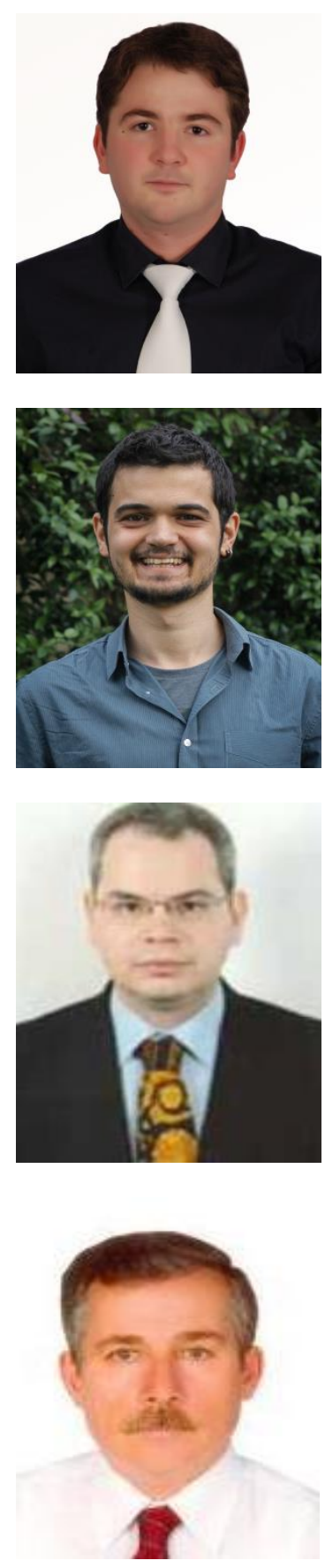

Tanju ERGEN has received his bachelor and master degrees in Aeronautical Engineering from Istanbul Technical University in 2013 and 2016 respectively. He is currently a PhD student in the same university.

Tamer SENER has received his bachelor and master degrees in Aeronautical Engineering from Istanbul Technical University in 2016 and 2019 respectively. He is currently a PhD student in the same university.

Prof. Dr. Onur TUNCER has received his bachelor degree in Mechanical Engineering from Middle East Technical University and PhD from Louisiana State University in 2001 and 2006 respectively. He has been teaching Combustion, Fluid Mechanics, Engineering Mathematics and Heat Transfer courses at Istanbul Technical University, Faculty of Aeronautics and Astronautics since 2009.

Prof. Dr. A. Cihat BAYTAŞ has received his $\mathrm{PhD}$ degree from Istanbul Technical University Nulear Energy Institude in 1988. He has been teaching Fluid Mechanics, Aircraft Icing, Convective Heat Transfer and Heat Transfer courses at Istanbul Technical University, Faculty of Aeronautics and Astronautics since 2002. 